\title{
Beyond the Expected Activities: The Role of Impulsivity between Emotional Intelligence and Employee Creativity
}

\author{
Ebru Gozukara $^{1}$ \\ ${ }^{1}$ T. C. Istanbul Arel University, Turkey \\ Correspondence: Ebru Gozukara, Department of Business Administration, Faculty of Economic and \\ Administrative Sciences T. C. Istanbul Arel University, 34537, Turkey. Tel: 90-532-501-9797. E-mail: \\ ebrugozukara@arel.edu.tr
}

Received: January 26, 2016

Accepted: February 16, 2016

Online Published: February 25, 2016

doi: 10.5539/ibr.v9n3p143

URL: http://dx.doi.org/10.5539/ibr.v9n3p143

\begin{abstract}
Individual creativity is considered as an individual phenomenon level that provides the production of new and extremely valuable ideas for organizations. Organizational level studies indicate that there are lots of factors examined in individual and group levels within organizations like innovation climate effecting individual creativity, group communication, leadership style and creativity core competences. This study is based on the employees of a company who are affected by the individual impulsivity behavior, providing positive increase in the performance of the company by the help of creativity features of the employees. Accordingly, individuals' behaviors leading to impulsivity are examined in a number of dimensions such as premeditation, urgency, sensation seeking and perseverance. These dimensions influence the creativity of employees. Impulsivity is an important psychological situation, studied in many individuals and generally in systematic level. In addition, this study examines the assumption that emotional intelligence, consisting self-emotion appraisal, other-emotion appraisal, use of emotion, regulation of emotion dimensions has an influence on the relation between employee impulsivity behavior and employee creativity. This study also examines whether the relationship among the impulsivity behavior, emotional intelligence and creativity of an employee changes with respect to gender.
\end{abstract}

Keywords: impulsivity behavior, emotional intelligence, employee creativity

\section{Introduction}

Impulsivity is a comprehensive subject due to its multidisciplinary structure and as a result doesn't have an agreed or collective definition. However it may be defined as the inability to avoid behaviors and acts according to situations (Milich \& Kramer, 1982) or incitation to act without any plan or thinking with the tendency of impulse (Eysenck \& Eysenck, 1977; Schalling, 1978); (Gordon, 1979); (Martin et al., 1994). Impulsivity is an attribution of personality that a person shows unpredictable behavior by the urgency of the moment. Accordingly, it refers to individuals who rush into quick decisions (Nederkoorn et al., 2006). These unpredictable behaviors can reveal creative and novel problem solving, opinions, works or behaviors due to the nature conceptualization of the creativity (Amabile, 1996). Emotional intelligence is one of the factors reported to have an impact on an individual's work behavior (Groves, McEnrue, \& Shen, 2008). This study focuses on the employees with the ability to effectively manage their emotions and use of emotional intelligence that have been found to show better creative performance when affected by the impulsive behavior.

\section{Theoretical Framework and Hypothesis Development}

\subsection{The Impulsivity and Individual Creativity of Employees}

There are different kinds of definitions of impulsivity suggesting that the behaviors occur without any premeditation or conscious assignment. Nearly all the definitions concerning the characterization of the impulsivity include characterizing features such as "acting on the spur of the moment" and "the difficulty in sufficient planning, focusing on a specific problem" (Moeller et al., 2001, Patton et al., 1995) Other definitions involve the sensation seeking and risk taking dimensions of the variable (Eysenck \& Eysenck, 1977), (Evren et al., 2011). In order to measure impulsive behavior self-report questionnaires and laboratory based tasks may be used while some other aspects can be calculated by using different measurement methods (Aichert et al., 2012; Cyders \& Coskunpinar, 2011; Dalley et al., 2008). In self-report questionnaires impulsivity includes dimensions 
such as sensation seeking, risk taking, lack of planning, perseverance, and acting on impulses (Whiteside \& Lynam, 2001); however, laboratory based tasks relate to dimensions like response inhibition or interference control, as well as impulsive choice tasks (e.g., delay discounting) and time estimation (Dougherty et al., 2005; Friedman \& Miyake, 2004; Nigg, 2000; Robbins et al., 2012). The general impulsive behavior through a time period may be measured by self-reported impulsivity scales. Thus observing an individual's behavior may cause a stronger trait level in personality (Cyders \& Coskunpinar, 2011).

Creativity has been evaluated especially in arts, music, advertising, psychology, management studies for decades, and now in business where the success factors are studied in detail, creativity comes to the fore (Koslow et al., 2003, 2006; Sasser \& Koslow, 2008; Verbeke et al., 2008b; Zhou \& George, 2003). The common characteristic of creativity is to generate ideas, alternatives or possibilities to the problems to be solved and to develop new ideas and convert the new and imaginative concept into reality. Thus organizations need highly creative employees to survive in the competitive business environment (Lassk \& Shepherd, 2013). Increase in creativity in workplaces in turn increases the employee performance, job satisfaction, and progress in business (Dubinsky \& Ingram, 1983; Wang \& Netemeyer, 2004). Creativity is the emergence of new ideas (Beesley \& Cooper, 2008) to build up a different impression in business environment, thus organizations must develop and encourage creative behavior among their employees (Nieves et al., 2014). The employee creativity is shaped by the individual factors and the context of the workplace (Shalley et al., 2004).

However the behavior of a leader is very important in producing creative and/or innovative outputs and has effect on employee's performance (Shalley \& Gilson, 2004). For example, a leader's behavior is the most important factor in the work environment, increasing or decreasing the creativity among the individuals (Amabile et al., 2004). From this point of view, as impulsivity is recognized as an individual's behavior it would have an impact on the employee creativity. This study utilizes both approaches to introduce a comprehensive model to predict the between the employee creativity and other variables examined.

Impulsivity is an unexpectedly performed activity which includes a self-referent nature of any kind of behavior instead of being precautious (Johnson et al., 2013). These unexpected activities which are called impulsive behaviors have some novelty feelings without regard for rules and regulations (Cloninger et al., 1993). Creativity skills usually have been thought to not be governed by any rules (Mumford et al., 1996). Accordingly it is hypothesized that;

H1: Premediation impulsive behavior positively related to individual creativity.

H2: Urgency impulsive behavior positively related to individual creativity.

H3: Sensation seeking impulsive behavior positively related to individual creativity.

H4: Perseverance impulsive behavior positively related to individual creativity.

\subsection{The Moderating Role of Emotional Intelligence}

Emotions are thought to be strong psychological forces that can influence employees in a workplace, in particular their behavior and performance (Kidwell et al., 2011). The term is described as the capability of an individual to "perceive, appreciate, handle, deal with and conceive his/her own and the others' feelings" and "to regulate their thoughts successfully in order to cope with the environmental and social difficulties and to achieve the desired responses" (Mayer \& Salovey, 2007; Van Rooy \& Viswesvaran, 2004; Mayer et al., 2008; Vigoda-Gadot \& Meisler, 2010). Studies on Emotional Intelligence (EI) are conducted in many fields such as management, human resources, organizational behavior literature and in performance evaluation of employees in workplaces (O’Boyle Jr. et al., 2011, Wisker \& Poulis, 2015). A well-organized relationship among employees, customers or leaders is a critical key for success in performance or creativity and especially in collaborative workplace environment. EI helps employee or leaders to create this medium of creativity (Mathew \& Gupta, 2015). EI has been also defined in five constructs related to the individuals in business environment: Knowing and managing one's emotions, motivating oneself by marshalling emotions, recognizing emotions in individuals, and managing emotions in others so as to handle relationships in workplace (Mathiew \& Gupta, 2015). Mathew et al. (2004) had serious comments on EI since the researches published on this subject does not contain any empirical arguments (Gibbs, 1995; Goleman, 1995, 1998). Nevertheless the concept and context of EI have been accepted in numerous studies as well (Davies et al., 1998; Mayer et al., 2007, 2004; Law et al., 2004; Chrusciel, 2006).

Palmer and Stough (2001) stated EI as "an individual's capacity to perceive, understand, integrate and manage one's own and other people's feelings and emotions and to act upon them in a reflective and rational manner". The application of these capabilities of an individual or employee will be professional and effective in business 
life or workplace environment. There are four dimensions of the concept of EI suggested by Mayer et al. (2007, 2004): (1) understanding, evaluating and expressing emotion; (2) using emotion to promote thinking; (3) understanding the temporal course and probable outcome of emotions; and (4) regulating emotions effectively. Van Rooy and Viswesvaran (2004) also described EI as the emotion required to guide thinking and action that can successfully cope with environmental demands and pressures.

Furthermore, the level of "emotional intelligence" in an individual is sensitive to the environment or its surroundings according to Zeidner et al. (2004). In order to have a net self-evaluation in individuals, high EI is needed. The strength of communication with employees in a correct manner in business environment, appropriate type of behavior control, changing of working conditions in a positive way are all evaluated as contributions to high EI (Ölçer et al., 2014). EI is a very important factor that enhances the creativity by generating open-minded, exciting working environments and motivating the workers to produce inspired ideas, which brings success at the end (Rego et al., 2007; Lassk \& Shepherd, 2013). Consequently, through the effect of emotional intelligence on environment and its surroundings, individual creativity skills can be affected by these emotions. When emotional intelligence shows strong existence on individual behaviors the impulsive behaviors could have a stronger impact on individual creativity. Thus H5 is developed as:

H5: Emotional intelligence shows a moderating effect between the relationship of impulsivity and individual creativity.

\section{Research Design and Measures}

To test the above hypotheses, multi-item scales adopted from or developed in prior studies for measurement of the variables were used. Research variables were measured using 5-point Likert scales ranging from "strongly disagree" (1) to "strongly agree" (5). A summary of the measures is as follows. For impulsivity, the survey items of impulsive behavior scale developed by Whiteside and Lynam (2001) are modified. Consistent with these researchers, eleven items are included to assess the premediation, twelve items to measure the urgency, ten items for perseverance and twelve items to measure the sensation seeking. For emotional intelligence contents (i.e., self_emotion appraisal, other emotion appraisal, use of emotion and regulation of emotion) the questionnaire items used by Law et al. (2004) are adapted. Individual creativity was measured using fifteen items adapted from a scale developed by Chae et al. (2015).

The research's conceptual model, based on previous studies, is given in Fig. 1, showing the impact of four antecedent factors-premediation, urgency, sensation seeking and perseverance-on individual creativity of employees. Employees' impulsive behaviors and its dimensions are hypothesized to have a direct influence on individual creativity of employees. Emotional intelligence is also hypothesized to moderate the relationship between impulsivity and individual creativity.

\section{Emotional Intelligence}

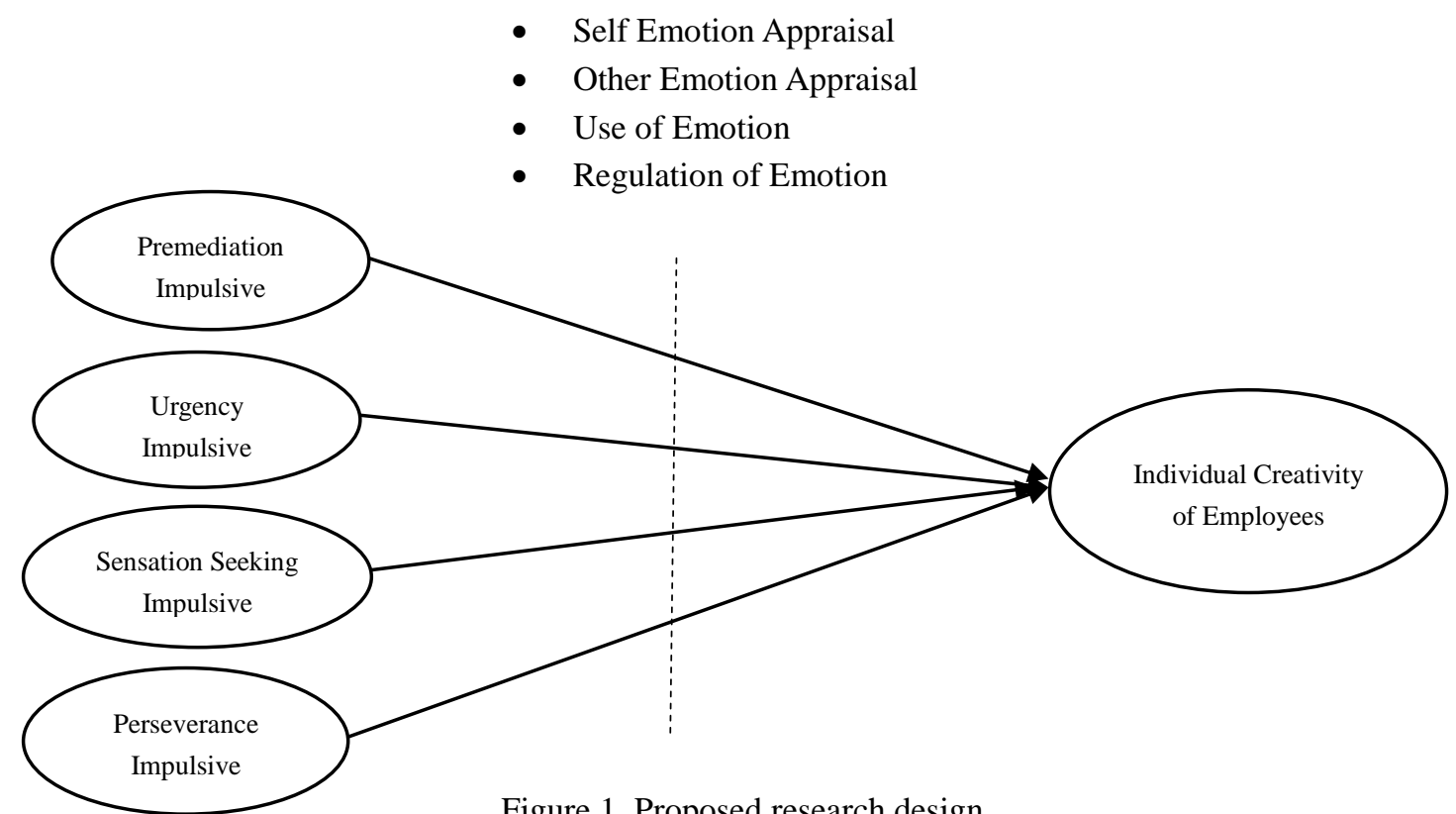

Figure 1. Proposed research design 


\section{Sampling}

After developing the new questionnaire items in English, two academics from US-based universities, evaluated the content and significance of the items to establish face validity. They did not note any difficulty in understanding the items or scales. These new and adopted questionnaire items were first translated into Turkish by one person and then retranslated into English by a second person using the parallel-translation method. The two translators then jointly reconciled all differences. A draft questionnaire was developed and then evaluated and revised in discussions with two academics from Turkey having the knowledge of organizational behaviors as expert judges. The suitability of the Turkish version of the questionnaires was then pre-tested by 15 part-time graduate students who are full-time employees working in industrial companies. In addition employees randomly selected from a diverse cross-section of companies located in Istanbul evaluated the content and significance of the items. Respondents did not demonstrate any difficulty in understanding the items or scales. After confirming the questionnaire items, the questionnaires were distributed and collected by the authors. The sampling population consisted of 218 employees located in Istanbul, Turkey.

Because of data screening, 53 out of 218 surveys were discarded. In this study sample, the respondents were working in departments of machinery and manufacturing (27\%), human resources (23\%), manufacturing (19\%), marketing (16\%), finance (12\%), public relations $(2 \%)$, and engineering and design $(1 \%)$. The mean age of the participants was $36.27($ s.d. $=5.12$ ) with $51 \%$ being female and $52 \%$ married. Of the participants, $48 \%$ had post-graduate degrees.

\section{Measure Validity, Reliability and Hypothesis Testing}

Impulsivity, emotional intelligence and individual creativity after the factor analysis applied to the data to test the hypotheses of the study are given in Table 1. The application of the factor analysis to the data to test the hypotheses of the study shows that the impulsivity measure is divided into four factors: Premediation, urgency, sensation making and perseverance. Emotional intelligence measure is divided into four factors as well: self-emotion appraisal, other-emotion appraisal, use of emotion and regulation of emotion. Individual creativity has been seen as one factor as in the original study. The factor loads of these dimensions are given in Table 1.

Table 1. Factor analysis results

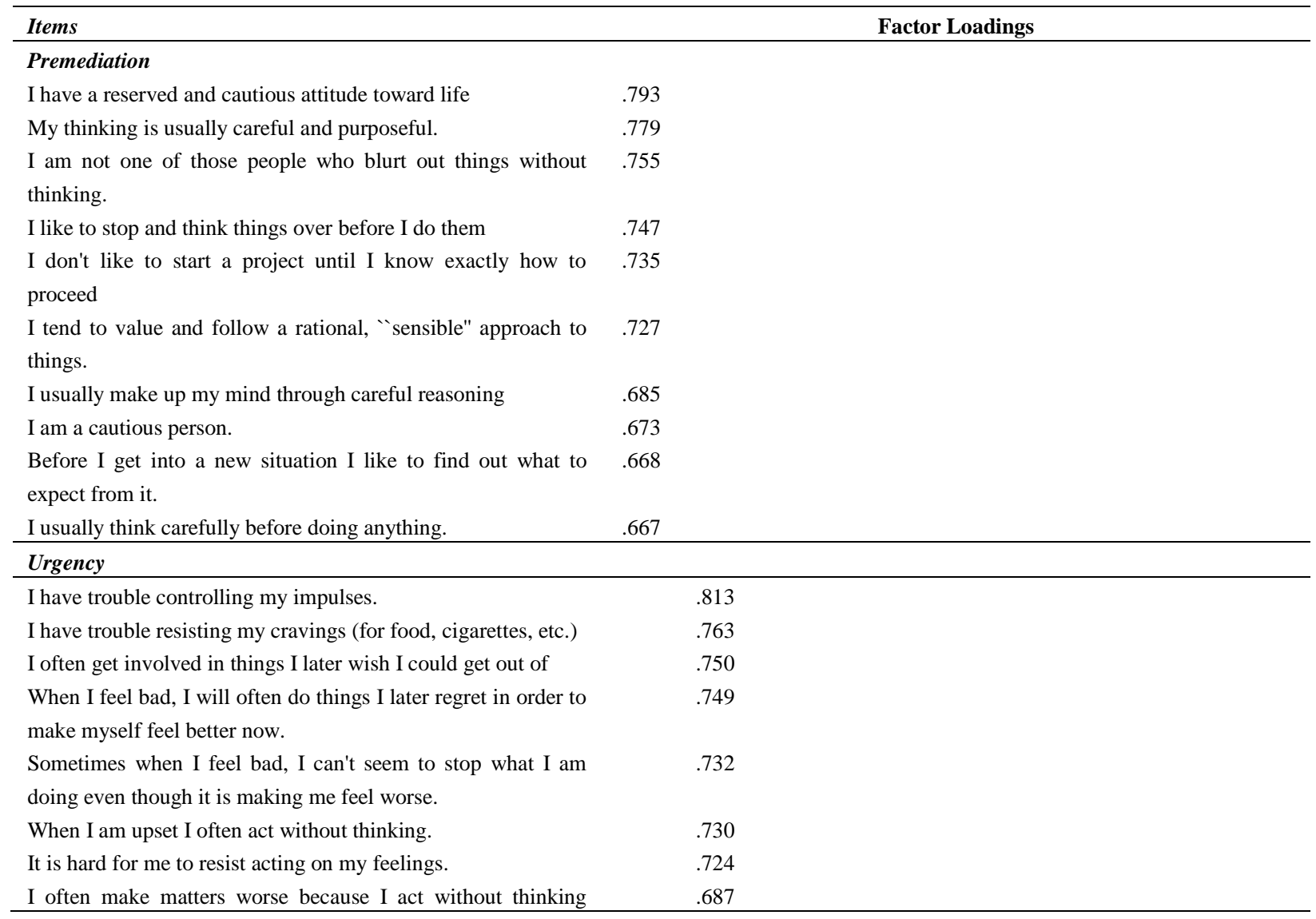


when I am upset.

In the heat of an argument, I will often say things that I later

regret.

I am always able to keep my feelings under control. (R)

Sometimes I do things on impulse that I later regret.

.609

\section{Sensation Seeking}

I generally seek new and exciting experiences and sensations.

I'll try anything once.

.848

.829

I like sports and games in which you have to choose your next

move very quickly.

I would enjoy water skiing

I quite enjoy taking risks.

I welcome new and exciting experiences and sensations, even

I would like to learn to fly an airplane.

.609

I sometimes like doing things that are a bit frightening.

I would enjoy the sensation of skiing very fast down a high .609

mountain slope.

I would like to go scuba diving.

I would enjoy fast driving.

607

\section{Perseverance}

I generally like to see things through to the end.

I tend to give up easily. (R)

Unfinished tasks really bother me.

Once I get going on something I hate to stop.

I concentrate easily.

I finish what I start.

I'm pretty good about pacing myself so as to get things done

on time.

I am a productive person who always gets the job done.

.631

Once I start a project, I almost always finish it.

.630

There are so many little jobs that need to be done that I

.628

sometimes just ignore them all. (R)

\section{Self-emotion appraisal}

I have a good sense of why I have certain feelings most of the time

$\begin{array}{lr}\text { I have a good understanding of my own emotions } & .878\end{array}$

I really understand what I feel

I always know whether or not I am happy

Other-emotion appraisal

I always know what my friends are feeling based on their

behavior

I am a good observer of others' emotions

I am sensitive to the feelings and emotions of others

I have a good understanding of the emotions of those around

me

Use of Emotion

I always set goals for myself and then try my best to achieve

them

I always tell myself I am a competent person

I am a self-motivating person

I always encourage myself to try my best

\section{Regulation of Emotion}

I am able to control my temper so that I can handle difficulties 


\begin{tabular}{ll}
\hline I am quite capable of controlling my own emotions & .731 \\
I can always calm down quickly after I get very angry & .653 \\
I have a lot of control over my emotions & .601 \\
\hline Individual Creativity & .896 \\
\hline Among my team members, I will be the first or nearly the first & .746 \\
to try our new idea or method. & .874 \\
I usually find new uses for existing methods or existing \\
equipment
\end{tabular}

To test research hypotheses, a serious of multiple linear regression models are conducted. However, before carrying out any analysis, the mean of items (composite scores) is calculated for each variable in the sample of 165 surveys from employees. The Spearman-Brown test of the interclass correlation (ICC) is used to determine the reliability of the aggregated perceptions (James, 1982). The results showed that ICC for all measures ranged from 0.64 to 0.94 , well above the 0.60 .

To test the moderating role of emotional intelligence between impulsivity and individual creativity of employees, a moderated multiple hierarchical regression analysis was used (Irwin \& McCelland, 2001). Because of the possibility of multicollinearity, the impulsivity and emotional intelligence constructs' measures were mean-centered before performing the linear regression model as suggested by Aiken and West (1991). Variance inflation factors (VIF) are estimated to examine multicollinearity levels and the results (VIFs, 10) were found to be below a harmful level (Neter et al., 1990). In addition the $\mathrm{R}^{2}$ regression is compared with and without the cross product to determine if the incremental $\mathrm{R}^{2}$ is significant. Results show that the inclusion of the interaction terms on the hierarchical regression added a significant variance explanation $(\mathrm{p}<.05)$ in the models in Table 2.

As shown in Table 3, premediation impacts the individual creativity $(b=.47, \mathrm{p}<.01)$, urgency impacts the individual creativity $(\mathrm{b}=.10, \mathrm{p}<.05)$, sensation seeking impact the individual creativity $(\mathrm{b}=.36, \mathrm{p}<.01)$, and perseverance impacts the individual creativity $(\mathrm{b}=.35, \mathrm{p}<.01)$. Thus, $\mathrm{H} 1, \mathrm{H} 2, \mathrm{H} 3, \mathrm{H} 4$ were supported. However, as shown in Table 3, the coefficients of the interaction terms demonstrate that, with a high level of emotional intelligence, the dynamics of sensation seeking have a positive association with individual creativity, partially supporting Hypothesis 5. The results also show that the effect of the dynamics of experiencing on impulsivity has an " $\square$ " shape with respect to the emotional intelligence (for instance, the coefficient of quadratic variable, emotional intelligence *dyn. of impulsivity is negatively significant), partially supporting Hypothesis 5 .

Table 2. Descriptive scales and construct correlations, and reliability estimates

\begin{tabular}{|c|c|c|c|c|c|c|c|c|c|c|c|}
\hline Variable & Mean & SD & $\mathbf{1}$ & 2 & 3 & 4 & 5 & 6 & 7 & 8 & 9 \\
\hline 1. Self Emotion Appraisal & 3.56 & .67 & - & & & & & & & & \\
\hline 2.Other Emotion Appraisal & 3.76 & .67 & $0.585^{* *}$ & - & & & & & & & \\
\hline 3. Use of Emotion & 3.57 & .64 & $0.679 * *$ & $0.460 * *$ & - & & & & & & \\
\hline 4. Regulation of Emotion & 3.66 & .53 & $0.679 * *$ & $0.446^{* * *}$ & $0.542 * *$ & - & & & & & \\
\hline 5. Premediation & 3.47 & .61 & $0.571 * *$ & $0.457 * *$ & $0.653 * *$ & $0.470 * *$ & - & & & & \\
\hline 6. Urgency & 3.44 & .60 & -0.037 & 0.036 & -0.009 & $-0.025^{* *}$ & -0.030 & - & & & \\
\hline 7. Sensation Seeking & 2.88 & .70 & $0.305 * *$ & $0.242 * *$ & $0.336 * *$ & $0.204 * *$ & $0.338 * *$ & $0.198 * *$ & - & & \\
\hline 8. Perseverance & 3.17 & .39 & $0.582 * *$ & $0.493 * *$ & $0.532 * *$ & $0.401 * *$ & $0.536^{* *}$ & -0.026 & $0.452 * *$ & - & \\
\hline 9. Individual Creativity & 3.65 & .52 & $0.475 * *$ & $0.472 * *$ & $0.557 * *$ & $0.395 * *$ & $0.653 * *$ & 0.098 & $0.517 * *$ & $0.572 * *$ & - \\
\hline \multicolumn{3}{|l|}{ Cronbach Alfa } & .91 & .84 & .78 & .82 & .63 & .89 & .78 & .89 & \\
\hline \multicolumn{3}{|l|}{ Composite Reliability(CR) } & .91 & .82 & .74 & .83 & .64 & .89 & .78 & .89 & \\
\hline \multicolumn{3}{|c|}{ Average Variation Extracted(AVE) } & .58 & .57 & .48 & .55 & .47 & .53 & .73 & .42 & \\
\hline
\end{tabular}

Note. ${ }^{*} \mathrm{p}<0.05,{ }^{*} \mathrm{p}<0.01$. 
Table 3. Moderating effect of emotional intelligence on individual creativity of employees

\begin{tabular}{|c|c|c|}
\hline & \multicolumn{2}{|c|}{ DV: Individual Creativity } \\
\hline & Model 1 & Model 2 \\
\hline \multicolumn{3}{|l|}{ Main Effects } \\
\hline Premeditation & $0.47 * * *$ & $0.58 * *$ \\
\hline Urgency & $0.10^{* *}$ & 0.45 \\
\hline Sensation Seeking & $0.36^{* * *}$ & $1.28 * * *$ \\
\hline Perseverance & $0.35 * * *$ & $0.66^{* *}$ \\
\hline Emotional Intelligence & 0.26 & 0.39 \\
\hline \multicolumn{3}{|l|}{ Interactions } \\
\hline Emotional IntelligencexPremediation & & -0.21 \\
\hline Emotional IntelligencexUrgency & & -0.39 \\
\hline Emotional IntelligencexSensation Seeking & & $-1.22 * * *$ \\
\hline Emotional IntelligencexPerseverance & & -0.53 \\
\hline $\mathrm{R}^{2}$ & .052 & .583 \\
\hline Adjusted $\mathrm{R}^{2}$ & .062 & .491 \\
\hline F value & $.019^{* *}$ & $.227 * * *$ \\
\hline
\end{tabular}

\section{Discussion and Future Research}

This study offers a contribution to the business management literature by empirically investigating the interrelationship among employee impulsivity behavior, emotional intelligence and individual creativity of employees. By highlighting the role of emotional intelligence in influencing individual creativity of employees, this study offers a framework for researchers and managers to visualize and understand the relationship between impulsivity behaviors and creativity skills of employees, thus enhancing the movement of the business and performance view.

First, the role of an employee's impulsivity on the individual creativity was empirically investigated. The results showed that, when an employee shows impulsive behavior in the workplace among premediation, urgency, sensation seeking or perseverance behaviors it directly impacts the individual creativity in a positive manner. Employees' behaviors come from their impulses. When an employee cannot keep his/her feelings under control or enjoy unusual sports or experiences like scuba diving, parachute jumping or fly an airplane, he/she tends to show creative thinking or complete tasks in efficient ways. Creative products are the outcomes of processes engaged in by creative individuals (Kim et al., 2010). This study indicates that individual creativity is affected by employees' impulsive behaviors, thus adding new insights to innovation management and organizational behavior.

The results of this study also show that emotional intelligence does not mediate the relationship between employees' impulsivity and individual creativity. On the other hand, it was confirmed that emotional intelligence might be particularly effective on the relation of sensation seeking and individual creativity. Specifically when employees under the conditions of low or high emotional intelligence about their emotional effort or interaction, their sensation seeking effect on their individual creativity can be more or less level. It is found that emotional intelligence impacts individual creativity with a " $\square$ " shape. This finding shows that when the emotional intelligence is at moderate level, the effect of sensation seeking of an employee on their creativity is weak. However, when an employee has more emotional intelligence, his/her sensation seeking behaviors strongly impact individual creativity.

From this research, management can understand the unknown side of impulsivity to increase individual creativity. Thus, management should focus on impulsivity as premediation, urgency, sensation seeking and perseverance dimensions to have more effective outcomes of the employee's creativity. Emotional intelligence in particular, is important to develop creativity of the employees. Being in the process of enhancing the strategies for the firm; managers should be placed the employees who has abilities of sensation seeking and emotional intelligence at crucial positions that needs creativity for the innovative outcomes.

There are some methodological limitations to this study. First, the sample size was relatively small. These sample characteristics may bias the results that would have emerged in a larger and slightly more heterogeneous sample population. Second, the data has been obtained from self-completed questionnaires. Thus, the common 
method bias could be a problem. To ensure that this problem was not a significant issue in the study, the single-common-method-factor approach was conducted to assess the common method variance (Podsakoff et al., 2003).

For the future research, organizational culture and innovative climate variables can be expanded in the research model. The relationship between the impulsivity and employees creativity can differ on the moderating effect of organizational culture and innovative climate.

\section{References}

Aichert, D. S., Williams, S. C. R., Möller, H. J., Kumari, V., \& Ettinger, U. (2012). Functional neural correlates of psychometric schizotypy: An fMRI study of antisaccades. Psychophysiology, 49, 345-356. http://dx.doi.org/10.1111/j.1469-8986.2011.01306.x

Aiken, L. S., \& West, S. G. (1991). Multiple regression: Testing and interpreting interactions. Newbury Park: Sage.

Amabile, T. M., Schatzel, E. A., Moneta, G. B., \& Kramer, S. J. (2004). Leader behaviors and the work environment for creativity: Perceived leader support. The Leadership Quarterly, 15(1), 5-32.

Amabile, T. M., Conti, R., Coon, H., Lazenby, J., \& Herron, M. (1996). Assessing the work environment for creativity. Academy of Management Journal, 39(5), 1154-1184.

Anderson, J. C., \& Gerbing, D. W. (1988). Structural equation modeling in practice: A review and recommended two-step approach. Psychological Bulletin, 103, 411-423. http://dx.doi.org/10.1037/0033-2909.103.3.411

Bechara, A. (2005). Decision making, impulse control and loss of willpower to resist drugs: A neurocognitive perspective. Native Neuroscience, 8(11), 1458-1463. http://dx.doi.org/10.1038/nn1584

Beesley, L. G., \& Cooper, C. (2008). Defining knowledge management (KM) activities: Towards consensus. Journal of Knowledge Management, 12(3), 48-62.

Chae, S., Seo, Y., \& Lee, K. C. (2015). Effects of task complexity on individual creativity through knowledge interaction: A comparison of temporary and permanent teams. Computers in Human Behavior, 42, 138-148. http://dx.doi.org/10.1016/j.chb.2013.10.015

Chrusciel, D. (2006). Considerations of emotional intelligence (EI) in dealing with change decision management. Management Decision, 44(5), 644-657. http://dx.doi.org/10.1108/00251740610668897

Cyders, M. A., \& Coskunpinar, A. (2011). Measurement of constructs using self-report and behavioral lab tasks: Is there overlap in nomothetic span and construct representation for impulsivity? Clinical Psychology Review, 31(6), 965-982. http://dx.doi.org/10.1016/j.cpr.2011.06.001

Dalley, J. W., Mar, A. C., Economidou, D., \& Robbins, T. W. (2008). Neurobehavioral mechanisms of impulsivity: Fronto-striatal systems and functional neurochemistry. Pharmacology Biochemistry and Behavior, 90(2), 250-260.

Dougherty, D. M., Mathias, C. W., Marsh, D. M., \& Jagar, A. A. (2005). Laboratory behavioral measures of impulsivity. Behavior Research Methods, 37(1), 82-90.

Dubinsky, A. T., \& Ingram, T. N. (1983). Important first-line sales management qualifications: What sales executives think. Journal of Personal Selling \& Sales Management, 3(1), 18-25.

Eysenck, S. B., \& Eysenck, H. J. (1977). The place of impulsiveness in a dimensional system of personality description. British Journal of Social and Clinical Psychology, 16, 57-68. http://dx.doi.org/10.1111/j.2044-8260.1977.tb01003.x

Evren, C., Durkaya, M., Evren, B., Dalbudak, E., \& Cetin, R. (2012). Relationship of relapse with impulsivity, novelty seeking and craving in male alcohol-dependent inpatients. Drug and Alcohol Review, 31, 81-90. http://dx.doi.org/10.1111/j.1465-3362.2011.00303.x

Friedman, N. P., \& Miyake, A. (2004). The relations among inhibition and interference control functions: A latent-variable analysis. Journal of experimental psychology: General, 133(1), 101.

Fornell, C., \& Larcker, D. F. (1981). Evaluating structural equation models with unobservable variables and measurement error. Journal of Marketing Research 18, 39-51.

Fuster, J. M. (2008). The prefrontal cortex. London: Elsevier.

Gibbs, G., \& Simpson, C. (2004). Conditions under which assessment supports students' learning. Learning and 
Teaching in Higher Education, 1(1), 3-31.

Goleman, D. (1998). Working with emotional intelligence. Bantam.

Gordon, M. (1979). The assessment of impulsivity and mediating behaviors in hyperactive and non-hyperactive boys. Journal of Abnormal Child Psychology, 7, 317-326. http://dx.doi.org/ 10.1007/BF00916541

Groves, K. S., McEnrue, M. P., \& Shen, W. (2008). Developing and measuring the emotional intelligence of leaders. Journal of Management Development, 27(2), 225-250.

Irwin, J. R., \& McClelland, G. H. (2001). Misleading heuristics and moderated multiple regression models. Journal of Marketing Research, 38(1), 100-109. http://dx.doi.org/0.1509/jmkr.38.1.100.18835

James, L. R. (1982). Aggregation bias in estimates of perceptual agreement. Journal of Applied Psychology, 67, 219-29.

Johnson, S. L., Carver, C. S., Mule, S., \& Joormann, J. (2013). Impulsivity and risk for mania: Towards greater specificity. Psychology and Psychotherapy: Theory, Research and Practice, 86, 401-412. http://dx.doi.org/10.1111/j.2044-8341.2012.02078.x

Kidwell, B., Hardesty, D. M., Murtha, B. R., \& Sheng, S. (2011). Emotional intelligence in marketing exchanges. Journal of Marketing, 75(1), 78-95. http://dx.doi.org/10.1509/jmkg.75.1.78

Kim, K. H., Cramond, B., \& VanTassel-Baska, J. (2010). The relationship between creativity and intelligence. In J. C. Kaufman, \& R. J. Sternberg (Eds.), The Cambridge handbook of creativity (pp. 395-412). New York: Cambridge University Press.

Koslow, S., Sasser, S. L., \& Riordan, E. A. (2003). What is creative to whom and why? Perceptions in advertising agencies. Journal of Advertising Research, 43(1), 96-110.

Koslow, S., \& Sasser, S. L. (2008). Desperately seeking advertising creativity: Engaging an imaginative "3Ps" research agenda. Journal of Advertising, 37(4), 5-20.

Lassk, F. G., \& Shepherd, C. D. (2013). Exploring the relationship between emotional intelligence and salesperson creativity. Journal of Personal Selling \& Sales Management, 33(1), 25-37. http://dx.doi.org/10.2753/PSS0885-3134330103

Law, K. S., Wong, C. S., \& Song, L. J. (2004). The construct and criterion validity of emorional intelligence and its potential utility for management studies. Journal of Applied Psychology, 89, 483-496. http://dx.doi.org/10.1037/0021-9010.89.3.483

Mathew, M., \& Gupta, K. S. (2015).Transformational Leadership: Emotional Intelligence. SCMS Journal of Indian Management, 11(2).75-89.

Matthews, G., Roberts, R. D., \& Zeidner, M. (2004). Seven myths about emotional intelligence. Psychological Inquiry, 15, 179-196.

Martin, C. S., Earlywine, M., Blackson, T. C., Vanyukov, M. M., Moss, H. B., \& Tarter, R. E. (1994). Aggressivity, inattention, hyperactivity, and impulsivity in boys at high and low risk for substance abuse. Journal of Abnormal Child Psychology, 22(2), 177-203.

Mayer, J. D., Salovey, P., \& Caruso, D. R. (2004). Emotional intelligence: Theory, findings, and implications. Psychological Inquiry, 197-215.

Mayer, J. D., \& Salovey, P. (2007). Mayer-Salovery-Caruso Emotional Intelligence Test. Multi-Health Systems Incorporated. http://dx.doi.org/10.1016/j.pnpbp.2012.09.013

Mayer, J. D., Salovey, P., \& Caruso, D. R. (2008). Emotional intelligence: New ability or eclectic traits? American Psychologist, 63(6), 503.

Milich, R., \& Kramer, J. (1982). Socialization and peer relations in hyperactive children. In K. Gadow, \& I. Bialer (Eds.), Advances in Learning and Behavioral Disabilities (pp. 283-339). Greenwich, CT: JAI Press. http://dx.doi.org/10.1177/002221948401700911

Moeller, F. G., Barratt, F. S., Dougherty, D. M., Schmitz, J. M., \& Swann, A. C. (2001). Psychiatric aspects of impulsivity. Am J Psychiatry, 158, 1783-1793.

Mumford, M. D., Baughman, W. A., Threlfall, K. V., Supinski, E. P., \& Costanza, D. P. (1996). Process-based measures of creative problem-solving skills: I. Problem construction. Creativity Research Journal, 9, 63-76.

Nederkoorn, C., Smulders, F. T., Havermans, R. C., Roefs, A., \& Jansen, A. (2006). Impulsivity in obese women. 
Appetite, 47(2), 253-256. http://dx.doi.org/10.1016/j.appet.2006.05.008

Neter, J., Wasserman, W., \& Kutner, M. (1990). Applied hnear stahstical models (2nd ed). Richard E. Irwin, Inc., Homewood, IL.

Nigg, J. T. (2000). On inhibition/disinhibition in developmental psychopathology: Views from cognitive and personality psychology and a working inhibition taxonomy. Psychological Bulletin, 126(2), 220. http://dx.doi.org/10.1037/0033-2909.126.2.220

O’Boyle, J. E. H., \& Williams, L. J. (2011). Decomposing model fit: Measurement vs. theory in organizational research using latent variables. Journal of Applied Psychology, 96(1), 1.

Ölçer, F., Florescu, M. S., \& Năstase, M. (2014). The Effects of Transformational Leadership and Emotional Intelligence of Managers on Organizational Citizenship Behaviors of Employees. Review of International Comparative Management, 15(4), 385-401.

Palmer, B., \& Stough, C. (2001). Workplace SUEIT: Swinburne University Emotional Intelligence Test-Descriptive Report. Organisational Psychology Research Unit, Swinburne University, AU.

Patton, J. H., Stanford, M. S., \& Barratt, E. S. (1995). Factor structure of the Barratt Impulsiveness Scale. J Clin Psychol, 51, 68-74.

Podsakoff, P. M., MacKenzie, S. B., Lee, J. Y., \& Podsakoff, N. P. (2003). Common method biases in behavioral research: A critical review of the literature and recommended remedies. Journal of Applied Psychology, 88(5), 879. http://dx.doi.org/10.1037/0021-9010.88.5.879

Rego, A., Sousa, F., Pina, C. M., Correia, A., \& Saur-Amaral, I. (2007). Leader Self Reported Emotional Intelligence and Perceived Employee Creativity: An Exploratory Study. Creativity and Innovation Management, 16(3), 250-264. http://dx.doi.org/10.1111/j.1467-8691.2007.00435.x

Robbins, T. W., Gillan, C. M., Smith, D. G., Wit, S., \& Ersche, K. D. (2012). Neurocognitive endophenotypes of impulsivity and compulsivity: Towards dimensional psychiatry. Trends in cognitive sciences, 16(1), 81-91. http://dx.doi.org/10.1016/j.tics.2011.11.009

Schalling, D. (1978). Psychopathy-related personality variables and the psychophysiology of socialization. In R. D. Hare, \& D. Schalling (Eds.), Psychopathic Behaviour: Approaches to Research (pp. 85-105). New York: Wiley.

Shalley, C. E., Zhou, J., \& Oldham, G. R. (2004). The effects of personal and contextual characteristics on creativity: Where should we go from here? Journal of Management, 30(6), 933-958. http://dx.doi.org/10.1016/j.jm.2004.06.007

Shalley, C. E., \& Gilson, L. L. (2004). What leaders need to know: A review of social and contextual factors that can foster or hinder creativity. The Leadership Quarterly, 15(1), 33-53. http://dx.doi.org/10.1016/j.leaqua.2003.12.004

Van, R. D. L., \& Viswesvaran, C. (2004). Emotional intelligence: A meta-analytic investigation of predictive validity and nomological net. Journal of Vocational Behavior, 65(1), 71-95. http://dx.doi.org/10.1016/S0001-8791(03)00076-9

Vigoda, G. E., \& Meisler, G. (2010). Emotions in management and the management of emotions: The impact of emotional intelligence and organizational politics on public sector employees. Public Administration Review, 70(1), 72-86.

Wang, G., \& Netemeyer, R. G. (2004). Salesperson creative performance: Conceptualization, measurement, and nomological validity. Journal of Business Research, 57(8), 805-812. http://dx.doi.org/10.1016/S0148-2963(02)00483-6

Whiteside, S. P., \& Lynam, D. R. (2001). The five factor model and impulsivity: Using a structural model of personality to understand impulsivity. Personality and Individual Differences, 30(4), 669-689. http://dx.doi.org/10.1016/S0191-8869(00)00064-7

Wisker, Z. L., \& Poulis, A. (2015). Emotional Intelligence and Sales Performance. A Myth or Reality? International Journal of Business and Society, 16(2), 185.

Zeidner, M., Matthews, G., \& Roberts, R. D. (2004). Emotional intelligence in the workplace: A critical review. Applied Psychology, 53(3), 371-399. http://dx.doi.org/ 10.1111/j.1464-0597.2004.00176.x

Zhou, J., \& George, J. M. (2003). Awakening employee creativity: The role of leader emotional intelligence. The 
leadership quarterly, 14(4), 545-568.

Zuckerman, M., Kuhlman, D. M., Thornquist, M., \& Kiers, H. (1991). Five (or three) robust questionnaire scale factors of personality without culture. Personality and Individual Differences, 12, 929-941.

\section{Copyrights}

Copyright for this article is retained by the author(s), with first publication rights granted to the journal.

This is an open-access article distributed under the terms and conditions of the Creative Commons Attribution license (http://creativecommons.org/licenses/by/3.0/). 